\title{
Complex pulmonary aspergilloma treated by cavernostomy
}

\section{Tratamento do aspergiloma pulmonar complexo por cavernostomia}

\author{
Paula dos Santos Marsico Pereira da Silva, ACbC-RJ'; Giovanni Antonio Marsico, TCBC-RJ'; Marcell Alex Ferraz Araujo'; \\ Fernando Soares Vannucci Braz, TCBC-RJ'; Heron Teixeira Andrade dos Santos, ACBC-RJ'; Gustavo Lucas Loureiro'; \\ ANDERSON FONTES ${ }^{1}$
}

A B S T R A C T

\begin{abstract}
Objective: To evaluate the effectiveness of cavernostomy in patients with complex fungal balls. Methods: We analyzed the medical records of patients undergoing cavernostomy between January 2005 and May 2013, evaluating: age, gender, preoperative signs and symptoms, predisposing disease, preoperative tests, location of the aspergilloma, etiologic agent, cavernostomy indication, postoperative outcome. Results: Ten patients were male. The mean age was 42.9 years (34-56). The most frequent symptom was repeated pulmonary bleeding. Cavernostomy was proposed for patients at high risk for lung resection. It was performed in 17 patients and all of them had pulmonary tuberculosis sequelae, with cavitations. The indication in all cases was hemoptysis and elimination of phlegm. The cavernostomies were performed in a single surgical procedure. In all 17 patients the cavity was left open after the withdrawal of the mycetoma. In all patients hemoptysis ceased immediately. Operative mortality was 9.5\% (1). Conclusion: cavernostomy is an effective treatment alternative in patients at high risk. It may be useful in some patients with complex aspergilloma, irrespective of lung function or bilateral disease. It is technically easy, has low-risk, saves parenchyma, and may be performed in a single operative time.
\end{abstract}

Key words: Hemoptysis.Tuberculosis. Aspergillosis. Thoracotomy.

\section{INTRODUCTION}

T he formation of pulmonary intracavitary fungal ball (aspergilloma) results from located colonization of a preformed or natural airspace. It occurs in $10 \%$ to $20 \%$ of tuberculosis healed cavities. Less frequently, it ensues in lung cavities resulting from necrotizing infection, bronchiectasis, bronchial cysts, emphysema bubbles, sarcoidosis, radiotherapy and lung cancer with cavitation. The Aspergillus fumigatus is the causative agent in over $90 \%$ of cases. The fungal spores, though of low virulence, may form the aspergilloma, especially in immunocompetent hosts ${ }^{1-6}$.

Pulmonary aspergilloma can be classified into simple and complex. The simple form presents as a isolated cavity with thin walls, surrounded by normal lung parenchyma. The most common is the complex form, where cavities have thick walls surrounded by fibrotic lung tissue, stiff hilar structures, vascular adhesions and obliteration of the pleural cavity. The changes are observed more frequently in sequelae of pulmonary tuberculosis ${ }^{7-11}$.

The volume of hemoptysis caused by the fungal ball is variable, however with frequent risk of causing death by asphyxiation. Where the clinical conditions permit, the definitive treatment of symptomatic pulmonary fungal ball is pulmonary resection. Several reports show that lung resections are associated with morbidity of $15 \%-78 \%$, and mortality of $0 \%-44 \%$. The discrepancies observed are mainly related to patient selection criteria, the extent of resection and the underlying lung disease ${ }^{4-7}$.

Lung resection of a symptomatic intracavitary fungal ball is not always feasible in those with compromised pulmonary function and / or extensive bilateral pulmonary disease. Therefore, in selected cases, exception surgical procedures are necessary, such as cavernostomy ${ }^{12-16}$.

This study aims to evaluate the effectiveness of cavernostomy in patients with complex fungal ball.

\section{METHODS}

We retrospectively reviewed the charts of 17 patients with intracavitary, complex pulmonary aspergilloma (fungal ball), submitted to cavernostomy at the Andaraí Federal Hospital, Ministry of Health, Rio de Janeiro, from January 2005 to May 2013. Inclusion criteria were: finding of the classic image of pulmonary intracavitary content in the conventional x-ray and / or computed tomography,

1. Thoracic Surgery Service, Andaraí Federal Hospital, Ministry of Health, Rio de Janeiro, RJ, Brazil. 
suggestive of fungal ball (Figures 1 and 2 ) in patients with recurrent hemoptysis; compromised pulmonary functional capacity, temporary or permanent, or possibility of pulmonary resection, which would, due to technical implications, result in significant loss of functioning lung parenchyma. We evaluated: age, gender, preoperative signs and symptoms, predisposing disease, preoperative tests, location of aspergilloma, etiologic agent, indication of cavernostomy, postoperative outcome. Bronchoscopy was routinely performed in the presence or absence of hemoptysis in all patients. The access and the choice of incision were based on the location of the fungal ball after analysis of chest radiographs and computed tomography.

\section{RESULTS}

Ten patients were men and seven women, aged between 34-56 years old, average 38.9. All patients had pulmonary tuberculosis sequelae and complex pulmonary aspergilloma, one being HIV-positive. In one patient had a relapsed fungus, having been subjected to cavernostomy at another hospital four years before.

The main complaints were: repeated pulmonary bleeding, uttered by blood sputum, hemoptysis with volume ranging from $400 \mathrm{ml}$ and $750 \mathrm{ml}$ in 24 hours, chronic cough, abundant purulent expectoration and respiratory infections. Eleven patients had digital clubbing.

In 13 patients lung function did not allow resection or there was an increased risk for the realization of the lobectomy or pneumonectomy. In four, pulmonary resection was possible, but due to technical implications, there would be great loss of functioning lung parenchyma.

In 10 patients the colonized lung cavities were located in the right lung, and seven on the left. In 16 patients the aspergilloma was located in the upper third of the lungs, and in one in the apical segment of the right lower lobe. In ten patients, pulmonary tuberculosis sequelae were bilateral. Two patients underwent embolization of bronchial arteries, but in both bleeding recurred.

All cavernostomies were performed under general anesthesia. Eleven patients used an endotracheal doublelumen tube, and six, single-lumen. In three patients cavernostomy was held during massive hemoptysis. In 14, a longitudinal incision was made in the midaxillary region, approximately $4.5 \mathrm{~cm}$ long. In one patient, the access was made in the third intercostal space on the left midclavicular line; and in two patients the access was performed in the interscapular region, one in the third intercostal space on the right and the other in the sixth intercostal space. All individuals had pleuropulmonary adhesions. In 14 patients, the incision planes were left wide open and the wound spontaneous closure occurred between the 30th and the 40th day after surgery. In three patients the skin was approximated to the edge of the cavity (marsupialization) with single stitches of absorbable sutures. In two, the closing

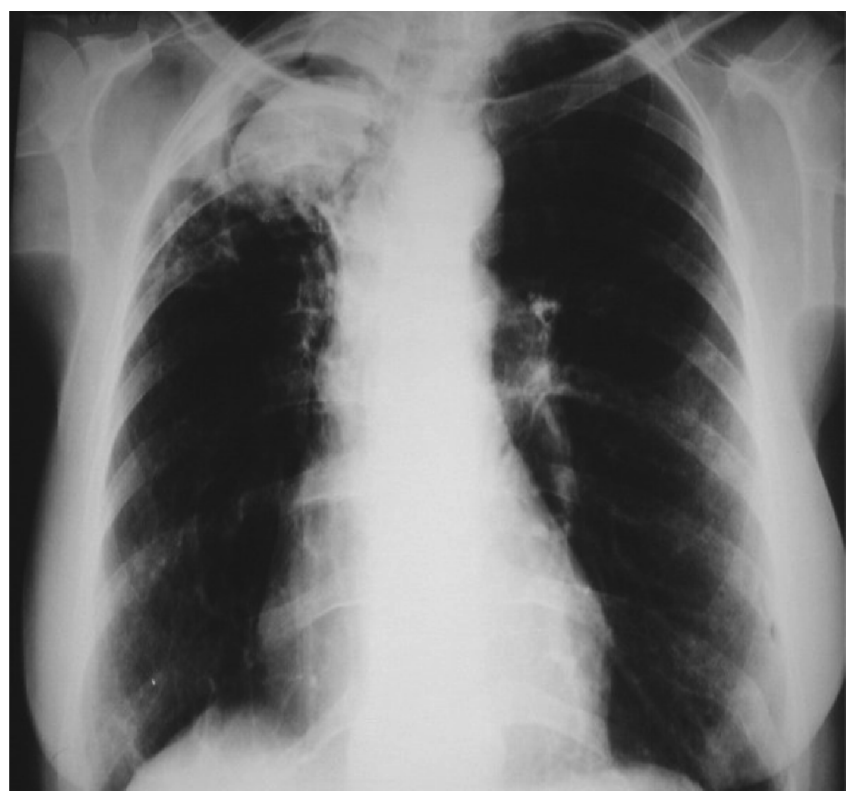

Figure 1 - Right cavity with great fungal ball.

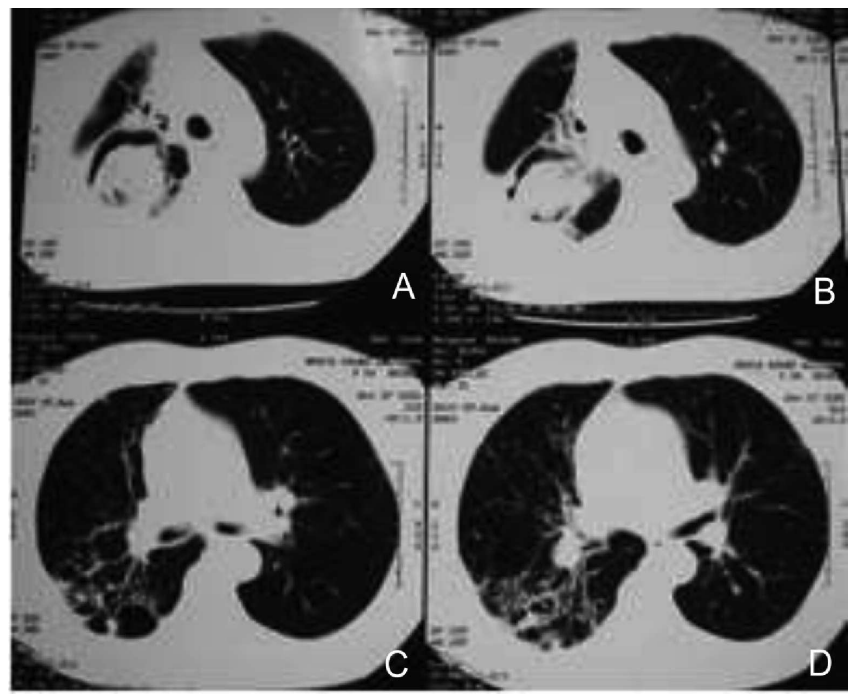

Figure 2 - $\quad$ Right fungal ball $(A, B)$ and bronchiect asis $(C, D)$.

of marsupialization occurred around the fourth month after the operation; the other patient died. The cavity was kept partially occluded with a dressing, removed after 24 hours. On subsequent days, the spontaneous elimination of residual fungi contents were frequent. None of the patients required mechanical ventilation in the postoperative period.

After cavernostomy (Figure 3), pulmonary bleeding stopped in all 17 patients. Aspergillus fumigatus was the etiologic agent in 16 subjects. Aspergillus niger was isolated from one. Four individuals developed subcutaneous emphysema, without clinical significance. In one, it was necessary to review the hemostasis of the edges of the pneumostomy incision. Two patients developed pneumonia and one (5.8\%) of them died on the 30th day after surgery. He had extensive bilateral pulmonary lesions and had undergone cavernostomy during hemoptysis. 
The follow-up of the 16 remaining patients ranged from three months to five years. In 15 there was no recurrence of hemoptysis in the operated lung, with significant improvement of cough and sputum. One patient presented with sparse hemoptysis after ten months of follow-up. Two patients who had bilateral residual lesions showed new hemoptysis five months and nine months after cavernostomy, however originated from the contralateral lung.

\section{DISCUSSION}

The sanitized tuberculous pulmonary cavity is the main predisposing factor for fungal colonization. The granulomatous fibrinopurulent exudate lining of the wall of the pulmonary cavity disappears, replaced by the epithelium. Inside the cavity there is an ideal temperature, absence of light, moisture and aerobiosis, which provides the colonization and proliferation of the conidia. Possibly due to local structural changes, phagocytosis of the fungal propagules by macrophages is impaired, thus facilitating the Aspergillus nesting. The medium necessary for the growth of the colonies results from the mucus produced on the bronchial epithelium, composed of glycosylated and nitrogenous substances. The pulmonary aspergilloma is variable in size and consists of a friable, irregular mass formed by hyphae, cell debris, blood and granulation tissue. Initially, the fungus adheres to the cavity wall, where it proliferates, but its own weight causes the detachment. Specific serology and cultures identify Aspergillus fumigatus in 98\% of patients $5-7,16-18$.

In our work, Aspergillus fumigatus was the etiologic agent in 16 cases and Aspergillus niger in one. In a series of patients with pulmonary tuberculosis sequelae followed for three years, $17 \%$ had aspergilloma formation 19. The presence of mycobacteria along with the fungal colonies is rare. Aspergillus fumigatus releases fumigalina, fumitoxin and gliotoxin, metabolites that inhibit the growth of Mycobacterium tuberculosis $5,6,9$.

The most common clinical manifestation of the fungal ball is hemoptysis, of variable volume. It is most frequent indication for surgical treatment, in $50 \%-83 \%$ of patients. Other signs and symptoms include sputum, chronic cough, dyspnea, digital clubbing, asthenia and weight loss $2,4,6,10,12$. All of our 17 patients presented daily, repeated, abundant hemoptysis as most frequent complaint, being the main cause of surgical indication. In pulmonary aspergilloma, the inflammatory process causes hypertrophy of the vessels, and collateral, parietal, intercostal and transpleural hypervascularization. Other hypotheses explaining the pulmonary bleeding are: a) friction and erosion caused by the fungal ball in the vascularized epithelium lining of the tuberculous cavity, but without penetrating the basal membrane, which is often thickened; b) release by the fungus of toxins and / or fibrinolytic

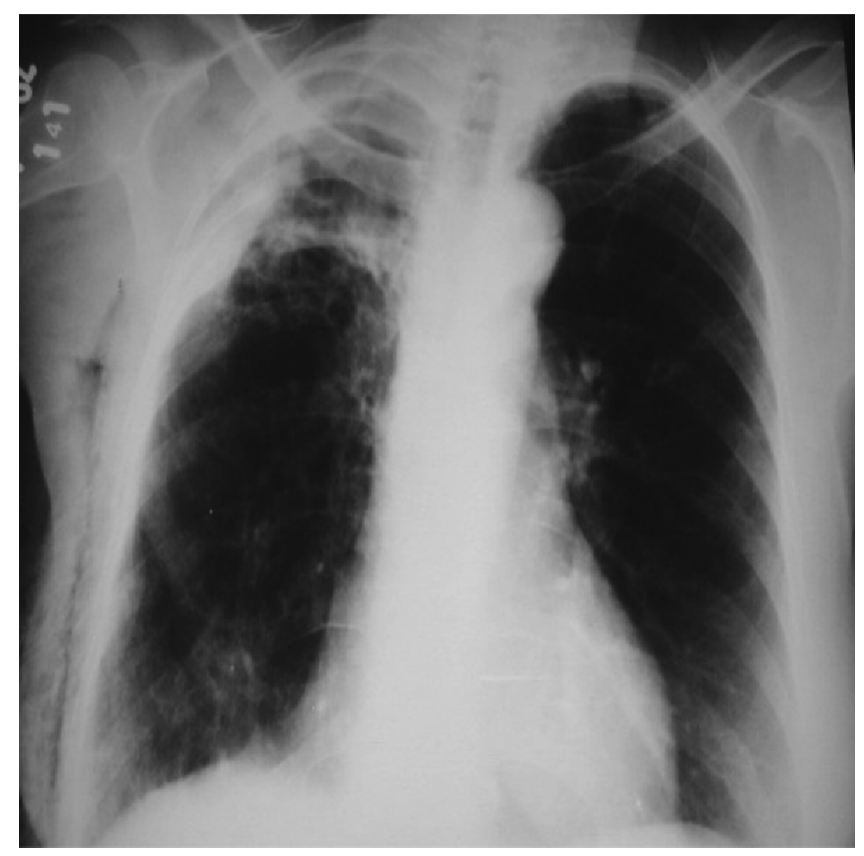

Figure 3 - After right cavernostomy.

enzymes; c) reactions of the antigen-antibody type elicited in the cavity wall. This would explain the higher percentage of failures of bronchial arteries embolization in cases of fungal ball, and the usual cessation of hemoptysis with the elimination or removal of the fungal ball 10,11,20.

Generally, the fungal ball is located in cavities in the apical and posterior segments of the upper lobes. The initial diagnosis is defined by conventional radiography and by computed tomography, although the crescent sign can also be observed in other situations, such as invasive aspergillosis, bronchial carcinoma, hematoma, chronic abscess, intracavitary clot and pulmonary hemangioma. The absence of the characteristic appearance on x-rays, however, does not rule out the existence of aspergilloma $1,10,11,13,18,19$

In 16 of our patients, the fungal ball was located in the upper third of the lungs, and in one in the apical segment of the lower lobe. Although rare, some patients may develop no symptoms, often having the simple form of fungal ball. The prevalence of asymptomatic patients can vary from $18 \%{ }^{10}$ to $22 \%{ }^{19}$.

Some authors $10,15,16,18,21$ indicate prophylactic pulmonary resection in asymptomatic patients to prevent massive hemoptysis. Nonetheless, spontaneous lysis of fungal ball may occur in $5-7 \%$ of cases.

The pneumonectomy indication is often complex in the case of fungal ball, since lung lesions are usually extensive. Resections are technically difficult, there is intense fibrosis installed around the cavity, obliteration of the pleural space, absence of interlobular fissures, stiff and difficult pulmonary hilum, intense collateral circulation, enlarged and tortuous bronchial arteries. lobar or segmental pulmonary resection is usually feasible in cases of simple 
fungal ball. However, the remaining lung does not always expand easily and fills the pleural space. The most common surgical complications are prolonged air leak, residual pleural space, hemorrhage, bronchopleural fistula and empyema $1,4,6,8,10,15,21$

The pulmonary resection approach to the fungal ball displays operative mortality from $0 \%$ to $44 \%$, and morbidity from $15 \%$ to $78 \%$. The improvement in survival is probably related to the most stringent criteria in the selection of patients, adequate lung capacity, the limited underlying lung disease and the extent of pulmonary resection. For the simple fungal ball operative mortality is similar to the one of the general population 4,8,10,13,18.

The cavernostomy is a surgical treatment option, especially in complex fungal ball in patients with pleuropneumonectomy indication and also in those with bilateral fungal balls. The cavernostomy is defined as necessary in patients with temporarily or permanently compromised lung function, with lower morbidity, mortality and functional deficit. It is considered a viable alternative, even to those that can be submitted to pulmonary resection $3,10,13,15,22-25$

The surgical decision in our 17 patients would be between pneumonectomy and cavernostomy. In 13 individuals the clinical conditions and lung function did not allow pneumonectomy. This was possible in four, however causing significant loss of functioning lung parenchyma.

Exceptionally, in debilitated and seriously ill patients, cavernostomy can be performed under local and / or regional anesthesia. In some cases, computed tomography is fundamental to locate the fungal ball and to the definition of the incision to access it. Operative techniques differ after the opening of the cavity and the removal of fungal ball $1,3,13,18,24$.

Regnard et al. performed 17 cavernostomies without registering deaths or major complications ${ }^{7}$. The cavity was kept occluded with compresses soaked in amphotericin B for several weeks. The procedure was effective in controlling hemoptysis. Compared to patients undergoing lobectomy or segmentectomy, the long-term survival was similar. They determined that, in patients with limited lung function and / or poor clinical condition, the operative risk of pulmonary resection increases, and emphasized that cavernostomy should be remembered, especially when there is indication for pleuropneumonectomy. Babatasi et al. held eight cavernostomies in patients with impaired lung function, with excellent results ${ }^{10}$. In four, the cavity was filled with chest wall muscles. Gebitekin et al. treated seven patients with intracavitary complex pulmonary aspergilloma and massive hemoptysis ${ }^{1}$. Four had bilateral pulmonary disease, impaired lung function and FEV $1<40 \%$, and two had bilateral cavitations. They performed cavernostomy and myoplasty simultaneously. After partial resection of rib, removal of fungal ball and coverage of intracavitary fistulas with mesh, they washed the cavity with amphotericin B. They used the pectoralis major, latissimus dorsi and trapezius muscles, the choice being based on the cavity location. Two 16F drains were left in the cavity, and were removed on the fifth day after surgery after the air leak ceased. Patients were extubated at the end of the procedure, without requiring mechanical ventilation. They administered Itracanozol 200 mg for two weeks preoperatively, and for three months postoperatively. One patient died after three months, from other causes. The remaining six were well in the period ranged from 18 to 83 months follow-up. In our patients, we did not use antifungals, either systemically, orally or locally in the cavities.

Rergkliang et al. performed six cavernostomies with muscle transposition in a single operative time ${ }^{3}$. They believe that the results and survival with cavernostomy are comparable to pulmonary resection, and recommend that, due to the ease of cavernostomy with muscle transposition, it should be performed in patients with impaired respiratory function, those with large pleural adhesions and in emergency situations where the study of lung function is not possible.

Oakley et al. held seven cavernostomies in patients with high operative risk, with $29 \%$ mortality ${ }^{14}$. Jewkes et al. performed the procedure in a series of nine patients with severely compromised lung function ${ }^{20}$. Four died, two of them with severe pneumonia that were attributed to the instillation of antifungal in the cavity.

Csekeo et al. treated 12 patients with pulmonary aspergilloma and compromised cardiopulmonary function ${ }^{13}$. In eight they performed pneumotomy, removal of the fungal ball and occlusion of the cavity with muscle; in the remaining four the cavity was left open. There was 1 (8.3\%) death caused by bleeding.

Caesar et al. performed 111 cavernostomies, simply removing the fungal ball after costectomy segment and pneumotomy ${ }^{15}$. The incision was left open for spontaneous closure. They recommend cavernostomy for patients with peripheral colonized cavities and in the elderly with impaired lung function. There were 15 (19.5\%) deaths, justified by the fact that cavernostomy had been performed in patients with worse clinical conditions and / or elderly. In $10(9 \%)$ patients, there was recurrence of hemoptysis, requiring lung resection.

In our study, we used a similar surgical technique in the cavernostomies: segmental resection of costal arch, cavity opening and removal of intracavitary fungal ball without myoplasty. In 14 patients the incision was left open and the healing took place spontaneously between 30 and 40 days. In three, we performed skin invagination to facilitate the healing and cleaning in the following days. The cavernostomies were performed in a single procedure.

Although rare, the fungal ball may recur after cavernostomy. However, the procedure can be repeated, even facilitated by the previously established path ${ }^{7,22}$. One of our patients had recurrent fungal ball, four years after 
cavernostomy at another hospital. The procedure was redone without any problems and the patient recovered uneventfully.

Guimarães et al. conducted cavernostomy on 38 patients with fungal ball, without rotation muscle flaps, 5 of whom died (13\%), four of these having being operated for massive hemoptysis, which increases the morbidity and mortality ${ }^{24}$. Three of our 17 patients were operated during episodes of massive hemoptysis, with 1 (5.8\%) death by pneumonia.

Our results suggest that cavernostomy was effective and can be performed in patients with complex fungal ball of peripheral location, with permanently or temporarily impaired pulmonary function, and in those in whom, due to technical problems, pulmonary resection would imply important loss of functioning parenchyma lung. In stable patients it demonstrated to be an easy-to-perform and low-risk procedure.

\title{
R E S U M O
}

\begin{abstract}
Objetivo: avaliar a efetividade da cavernostomia nos pacientes com bola fúngica complexa. Métodos: foram analisados os prontuários de pacientes submetidos à cavernostomia entre janeiro de 2005 e maio de 2013. Foram avaliados: idade, sexo, sinais e sintomas pré-operatórios, doença predisponente, exames pré-operatórios, localização do aspergiloma, agente etiológico, indicação da cavernostomia, evolução pós-operatória. Resultados: dez pacientes eram do sexo masculino. A média de idade foi 42,9 anos (34-56). O sintoma mais frequente foi o sangramento pulmonar repetido. A cavernostomia foi proposta para os pacientes com risco elevado para ressecção pulmonar, foi realizada em 17 pacientes e todos eles apresentavam sequelas de tuberculose pulmonar com lesões cavitárias. A indicação em todos os casos foi hemoptise e eliminação de catarro. As cavernostomias foram realizadas em tempo cirúrgico único. Nos 17 pacientes a caverna foi deixada aberta após a retirada do micetoma. Em todos os pacientes a hemoptise cessou imediatamente. A mortalidade operatória foi 1 (9.5\%). Conclusão: a cavernostomia é uma alternativa de tratamento efetivo em pacientes com risco elevado. Pode ser útil em alguns pacientes com aspergiloma complexo, independentemente da função pulmonar ou doença bilateral. É tecnicamente fácil, de baixo risco, poupa parênquima, e realizada em tempo operatório único.
\end{abstract}

\section{Descritores: Hemoptise. Tuberculose. Aspergilose. Toracotomia.}

\section{REFERENCES}

1. Gebitekin C, Sami Bayram A, Akin S. Complex pulmonary aspergilloma treated with single stage cavernostomy and myoplasty. Eur J Cardiothorac Surg. 2005;27(5):737-40.

2. Lee JG, Lee CY, Park IK, Kim DJ, Chang J, Kim SK, et al. Pulmonary aspergilloma: analysis of prognosis in relation to symptoms and treatment. J Thorac Cardiovasc Surg. 2009;138(4):820-5.

3. Rergkliang C, Chetpaophan A, Chittithavorn V, Vasinanukorn P. Surgical management of pulmonary cavity associated with fungus ball. Asian Cardiovasc Thorac Ann. 2004;12(3):246-9.

4. Akbari JG, Varma PK, Neema PK, Menon MU, Neelakandhan KS. Clinical profile and surgical outcome for pulmonary aspergilloma: a single center experience. Ann Thorac Surg. 2005;80(3):106772.

5. Unis G, Picon PD, Severo LC. Coexistência de colonização fúngica intracavitária (bola fúngica) e tuberculose ativa. J bras pneumol. 2005;31(2):139-43.

6. Kim YT, Kang MC, Sung SW, Kim JH. Good long-term outcomes after surgical treatment of simple and complex pulmonary aspergilloma. Ann Thorac Surg. 2005;79(1):294-8.

7. Regnard JF, Icard $P$, Nicolosi $M$, Spagiarri L, Magdeleinat $P$, Jauffret B, et al. Aspergilloma: a series of 89 surgical cases. Ann Thorac Surg. 2000;69(3):898-903.

8. Kabiri H, Lahlou K, Achir A, Al Aziz S, El Meslout A, Benosman A. Les aspergillomes pulmonaires: résultats du traitement chirurgical. À propos d'une série de 206 cas. Chirurgie. 1999;124(6):655-60.

9. Belcher JR, Plummer NS. Surgery in broncho-pulmonary aspergillosis. Br J Dis Chest. 1960;54:335-41.

10. Babatasi G, Massetti M, Chapelier A, Fadel E, Macchiarini P, Khayat $A$, et al. Surgical treatment of pulmonary aspergilloma: current outcome. J Thorac Cardiovasc Surg. 2000;119(5):906-12.
11. Park CK, Jheon S. Results of surgical treatment for pulmonary aspergiloma. Eur J Cardiothorac Surg. 2002;21(5):918-23.

12. Chen JC, Chang YL, Luh SP, Lee JM, Lee YC. Surgical treatment for pulmonary aspergilloma: a 28 year experience. Thorax. 1997;52(9):810-3.

13. Csekeo A, Agócs L, Egerváry M, Heiler Z. Surgery for pulmonary aspergillosis. Eur J Cardiothorac Surg. 1997;12(6):876-9.

14. el Oakley R, Petrou M, Goldstraw P. Indications and outcome of surgery for pulmonary aspergilloma. Thorax. 1997;52(9):813-5.

15. Cesar JM, Resende JS, Amaral NF, Alves CM, Vilhena AF, Silva FL. Cavernostomy $\mathrm{x}$ resection for pulmonary aspergilloma: a 32-year history. J Cardiothorac Surg. 2011;6:129.

16. Pecora DV, Toll MW. Pulmonary resection for localized aspergillosis. N Engl J Med. 1960;263:785-7.

17. Battaglini JW, Murray GF, Keagy BA, Starek PJ, Wilcox BR. Surgical management of symptomatic pulmonary aspergilloma. Ann Thorac Surg. 1985;39(6):512-6.

18. Daly RC, Pairolero PC, Piehler JM, Trastek VF, Payne WS, Bernatz PE. Pulmonary aspergilloma. Results of surgical treatment. J Thorac Cardiovasc Surg. 1986;92(6):981-8.

19. Aspergilloma and residual tuberculous cavities - the result of resurvey. Tubercle. 1970;51(3):227-45.

20. Jewkes J, Kay PH, Paneth M, Citron KM. Pulmonary aspergilloma: analysis of prognosis in relation to haemoptysis and survey of treatment. Thorax. 1983;38(8):572-8.

21. Massard G, Roeslin N, Wihlm JM, Dumont P, Witz JP, Morand G. Pleuropulmonary aspergilloma: clinical spectrum and results of surgical treatment. Ann Thorac Surg. 1992;54(6):1159-64.

22. Sagawa $M$, Sakuma $T$, Isobe $T$, Sugita $M$, Waseda $Y$, Morinaga $\mathrm{H}$, et al. Cavernoscopic removal of a fungus ball for pulmonary complex aspergilloma. Ann Thorac Surg. 2004;78(5):1846-8. 
23. Tseng $Y L, W u M H$, Lin MY, Lai WW. Intrathoracic muscle flap transposition in the treatment of fibrocavernous tuberculosis. Eur J Cardiothorac Surg. 2000;18(6):666-70.

24. Guimarães CA, Montessi J, Marsico GA, Clemente AM, Costa AMM, Saito E, et al. Pneumostomia (cavernostomia) no tratamento da bola fúngica. In: XII Congresso Brasileiro de Cirurgia torácica, 2001, Gramado/RS. J Pneumol. 2001. p. S5.

25. Shiraishi Y, Katsuragi N, Nakajima Y, Hashizume M, Takahashi N, Miyasaka Y. Pneumonectomy for complex aspergilloma: is it still dangerous? Eur J Cardiothorac Surg. 2006;29(1):9-13.
Received 15/12/2013

Accepted for publication 10/02/2014

Conflict of interest: none.

Source of funding: none.

\section{Mailing address:}

Paula dos Santos Marsico Pereira da Silva

E-mail: paulamarsico@hotmail.com 